\title{
Stem photosynthesis: new evidence highlights the contribution of phenotypic plasticity to the invasion success of Mikania micrantha
}

\author{
Jin Zheng ${ }^{1}$, Tai-Jie Zhang ${ }^{2}$, Bo-Hui Li $^{3}$, Wei-Jie Liang ${ }^{3}$, Qi-Lei Zhang ${ }^{3}$, Min-Ling Cai ${ }^{3}$, and \\ Changlian Peng 3 \\ ${ }^{1}$ Affiliation not available \\ ${ }^{2}$ Institute of Plant Protection, Guangdong Academy of Agricultural Sciences \\ ${ }^{3}$ South China Normal University
}

November 21, 2020

\begin{abstract}
Phenotypic plasticity affords invasive plant species the ability to colonize a wide range of habitats, but physiological plasticity of their stems is seldom recognized. Investigation of the stem plasticity of invasive plant species could lead to a better understanding of their invasiveness. We performed a pot experiment involving defoliation treatments and an isolated culture experiment to determine whether the invasive species Mikania micrantha exhibits greater plasticity in the stems than do three native species that co-occur in southern China and then explored the mechanism underlying the modification of its stem photosynthesis. Our results showed that the stems of M. micrantha exhibited higher plasticity in terms of either net or gross photosynthesis in response to the defoliation treatment. These effects were positively related to an increased stem elongation rate. The enhancement of stem photosynthesis in M. micrantha resulted from the comprehensive action involving increases in the Chl a/b ratio, D1 protein and stomatal aperture, changes in chloroplast morphology and a decrease in anthocyanins. Increased plasticity of stem photosynthesis may improve the survival of M. micrantha under harsh conditions and allow it to rapidly recover from defoliation injuries. Our results highlight that phenotypic plasticity promotes the invasion success of alien plant invaders.
\end{abstract}

Stem photosynthesis: new evidence highlights the contribution of phenotypic plasticity to the invasion success of Mikania micrantha

Jin Zheng ${ }^{1 \#}$, Tai-Jie Zhang²\#, Bo-Hui Li ${ }^{1}$, Wei-Jie Liang ${ }^{1}$, Qi-Lei Zhang ${ }^{1}$, Min-Ling Cai, Chang-Lian Peng ${ }^{1}$

${ }^{1}$ Guangdong Provincial Key Laboratory of Biotechnology for Plant Development, Guangzhou Key Laboratory of Subtropical Biodiversity and Biomonitoring, School of Life Sciences, South China Normal University, Guangzhou 510631,PR China

${ }^{2}$ Guangdong Provincial Key Laboratory of High Technology for Plant Protection, Institute of Plant Protection, Guangdong Academy of Agricultural Sciences, Guangzhou 510640, PR China

Corresponding author : Prof. Chang-Lian Peng

Email: pengchl@scib.ac.cn

Tel: +86-20-85217612;

Fax: +86-20-85211372.

\# These authors contributed equally to this work.

Running head : Plasticity of stem photosynthesis in 


\title{
Mikania micrantha
}

\begin{abstract}
Phenotypic plasticity affords invasive plant species the ability to colonize a wide range of habitats, but physiological plasticity of their stems is seldom recognized. Investigation of the stem plasticity of invasive plant species could lead to a better understanding of their invasiveness. We performed a pot experiment involving defoliation treatments and an isolated culture experiment to determine whether the invasive species Mikania micrantha exhibits greater plasticity in the stems than do three native species that co-occur in southern China and then explored the mechanism underlying the modification of its stem photosynthesis. Our results showed that the stems of $M$. micrantha exhibited higher plasticity in terms of either net or gross photosynthesis in response to the defoliation treatment. These effects were positively related to an increased stem elongation rate. The enhancement of stem photosynthesis in M. micrantha resulted from the comprehensive action involving increases in the Chl $a / b$ ratio, D1 protein and stomatal aperture, changes in chloroplast morphology and a decrease in anthocyanins. Increased plasticity of stem photosynthesis may improve the survival of M. micranthaunder harsh conditions and allow it to rapidly recover from defoliation injuries. Our results highlight that phenotypic plasticity promotes the invasion success of alien plant invaders.
\end{abstract}

Keywords : chloroplasts, ETR, Mikania micrantha , pigments, plasticity, stem photosynthesis

\section{Introduction}

Alien species invasion has been recognized as one of the most severe global ecological issues and environmental threats (Vitousek et al. , 1996; Mack et al., 2000). Alien species invasion also has substantial negative effects on community structure and function and has contributed to global loss of biodiversity (Courchamp et al., 2017). Determining the factors that contribute to the spread of plants in areas outside their native ranges is currently an important issue of research in invasion biology.

Phenotypic plasticity allows plants to cope with complex heterogeneous environments and is thus often cited as an important mechanism of plant invasion (Richards et al., 2006; Zenni et al., 2014). Phenotypic plasticity occurs when a single genotype alters its morphological, physiological and life-history traits in response to changing environmental conditions (Pigliucci, 2001). These adaptive changes can improve plant growth and fitness (Davidson et al. , 2011), particularly for clonal plants with low levels of genetic variation (Keser et al. , 2014; Geng et al. , 2016). According to an analysis of 133 invasive plant species, the invasion mechanisms in approximately $50 \%$ of them were related to phenotypic plasticity (Ren \& Zhang, 2009).

Plastic changes can occur in various organs (e.g., roots, stems and leaves). Because the roots and leaves function in resource acquisition, the magnitude of phenotypic plasticity in these organs is critical for plant ecological adaptability (Violle et al. , 2009). Because stems are not the major organs that capture resources from the environment, few studies have focused on the effects of stem plasticity on the viability of plant species.

Stems are connected to roots and leaves and function in supporting the leaves, flowers and fruits; transporting water, mineral elements and organic nutrients; and even carrying out photosynthesis, storing materials and functioning as vegetative propagules (Pate \& Jeschke, 1995; Nivot et al. , 2008). Nearly all green parts of stems can conduct photosynthesis, particularly those of young stems or twigs. Although stem photosynthesis is often lower than leaf photosynthesis, with maximum rates of up to $75 \%$ of those of leaf photosynthesis (Pfanz et al., 2002; Ávila et al., 2014), it has important functions in maintaining whole-plant carbon balance (Kocurek et al., 2020), especially in the case of defoliation events caused by insect attacks, leaf fungal pathogens, etc. (Pfanz \& Aschan, 2001), or under stress conditions when leaf photosynthesis is limited due to stomatal closure (Bossard \& Rejmanek, 1992; Cernusak \& Cheesman, 2015). Stem photosynthesis can refix $60 \%-90 \%$ of the $\mathrm{CO}_{2}$ respired from local tissues (Pfanz et al., 2002; Kocurek et al., 2020) and increase the growth of stems by 10\%-30\% (Cernusak \& Hutley, 2011; Bloemen et al., 2016). The carbohydrates produced by stem photosynthesis are involved in maintaining hydraulic function (Bloemen et al., 2016), refilling xylem vessels after embolism (Schmitz et al., 2012) and alleviating xylem vulnerability to cavitation (De 
Baerdemaeker et al., 2017). Furthermore, the $\mathrm{O}_{2}$ released from stem photosynthesis is important for preventing low-oxygen limitations of mitochondrial respiration in metabolically active stem tissues (Wittmann \& Pfanz, 2014). Stem photosynthesis is also associated with drought tolerance (Cernusak \& Cheesman, 2015; Ávila-Lovera \& Tezara, 2018) and is involved in maintaining sap flow flux (Gao et al., 2016). Based on the results of these previous studies, it can be predicted that if a species is capable of dynamically adjusting stem photosynthesis, its viability is greatly enhanced.

Mikania micrantha Kunth, commonly known as the 'mile-a-minute' weed, is a perennial herbaceous creeping vine belonging to the Asteraceae family and is native to Central and South America (Holm et al., 1977). It has caused substantial economic and ecological losses in plantation crops and commercial and secondary forests within its range of introduction, which includes tropical Asia, Pacific islands, Indian Ocean islands, and Florida in the US (Waterhouse, 1994; Manrique et al., 2011; Zhang et al., 2004; Day et al., 2016). In China, M. micrantha was introduced into Hong Kong in the late 1800s and has since spread throughout southern China (Wang et al., 2003). M. micrantha has been listed as one of the 10 worst weeds and one of the 100 worst invasive species in the world (Lowe et al., 2001). It grows extremely fast (up to $20 \mathrm{~cm}$ in a 24-h period) (Li et al., 2012), can climb to the top of plant canopies, forms dense thickets, outcompetes existing vegetation by blocking sunlight and releasing allelochemicals (Zhang et al., 2004), and ultimately leads to a loss of species diversity. Moreover, it can alter the soil microbial community structure and soil nutrient cycling in invaded areas (Li et al., 2006; Chen et al. , 2009).

The stems of M. micrantha are photosynthetic (Liu et al. , 2020), and once this species becomes established, it can rapidly expand via stems that creep along the ground or over other plants, forming clonal ramets. In this study, we hypothesized that the stems of $M$. micrantha are more plastic than those of the native species that co-occur in southern China. To test this hypothesis, we perform pot experiments to investigate whether there is a difference in photosynthesis performance and growth in response to defoliation treatment between $M$. micrantha and native species and then further revealed the mechanism through which stem photosynthesis is modified in M. micrantha by evaluating stomatal aperture, chlorophyll content, chlorophyll fluorescence, photosynthesis-related proteins and chloroplast ultrastructure. We also used isolated culture experiments to analyze the regeneration patterns and photosynthesis potential in stem cuttings of both M. micrantha and the native species.

\section{Martials and methods}

\section{Plant materials}

Both the invasive and native species selected are perennial herbaceous climbing vines that have green photosynthetic stems year round. The stems of all these species can be used for vegetative reproduction. Vigorous stems of the invasive species M. micrantha and the native species (Pharbitis nil, Paederia scandens ,Pueraria lobata) were collected from wild populations near the Guangdong Academy of Agricultural Sciences, Guangzhou, China, and cultivated as raw plant materials for subsequent culture.

\section{Defoliation tests}

We conducted exploratory tests involving artificial defoliation of the invasive and native species from April to September in 2018 and 2019. Stems of the invasive and native species were cut into approximately $15 \mathrm{~cm}$ long segments that each had one node, and any leaves attached to the nodes were removed. Afterward, the cuttings were cultivated in plastic pots $(15 \mathrm{~cm})$ filled with jiffy substrate (Jiffy Products International B.V., Moerdijk, The Netherlands). Each species was grown in more than 30 pots, which were placed under shade conditions during the first week after planting. The regenerated plantlets were then grown under greenhouse conditions and watered daily. When the potted plants reached approximately $20 \mathrm{~cm}$ in height, $1.1-\mathrm{m}$ bamboo sticks were inserted into the soil of the pots as climbing media for the plants. After reaching $40-50 \mathrm{~cm}$ in height, the potted plants of each species were evenly divided into two groups. One group was allowed to continue to grow under normal conditions, serving as the control. The other group was subjected to complete artificial defoliation for 30 days, in which all newly grown leaves were removed at 2-3 d intervals. Every 10 days, the lengths of the stems of both invasive and native species were measured. On day 20 of defoliation, 
gas exchange and structural observations were performed on the stems of the invasive and native species, and chlorophyll fluorescence was determined. After 30 days of defoliation, the survival rate of treated plants was determined. The average survival rates were calculated based on three replications.

To examine how stem photosynthesis changed in the invasive species, another batch of potted plants of the invasive species was prepared and treated as mentioned above. The changes in photosynthetic pigments (chlorophyll) and nonphotosynthetic pigments (anthocyanins), stomatal behavior, gas exchange and chlorophyll fluorescence, photosynthesis-related proteins (D1 and Rubisco) and chloroplast ultrastructure of the stems of the defoliation group were compared with those of the stems and leaves of the normal-growth group.

\section{Isolated stem culture}

Uniform stems of the invasive and native species were detached from plants cultivated in a garden. The stems were washed with tap water and cut into 10-cm-long segments. Five or 6 segments were placed into a $9 \mathrm{~cm}$ petri dish that contained two pieces of filter paper and $8 \mathrm{~mL}$ of distilled water and cultured in an RXZ growth chamber (Jiangnan Equipment Factory, Ningbo, China). The cultures were maintained at $28^{\circ} \mathrm{C} / 25^{\circ} \mathrm{C}$ (day/night) under a light/dark photoperiod of $14: 10 \mathrm{~h}$, irradiation of $\sim 40 \mu \mathrm{mol}$ photon $\mathrm{m}^{-2} \mathrm{~s}^{-1}$ and $70 \%$ relative humidity for 20 days. The survival rate, root length and electron transport rate (ETR) of the stems in the isolated cultures were then investigated.

\section{Determination of gas exchange}

An LI-6800 portable infrared gas analyzer (LI-COR, Inc., USA) was used to measure gas exchange parameters in the stems and leaves. Measurements of the net photosynthesis rate $\left(P_{\mathrm{n}}\right)$, stomatal conductance and the dark respiration rate $\left(R_{\mathrm{d}}\right)$ were conducted between 09:00 and 12:00 h on clear days at 800 and $0 \mu \mathrm{mol}$ photon $\mathrm{m}^{-2} \mathrm{~s}^{-1}$, respectively. Photosynthetically active radiation (PAR) was emitted from a red:blue $(9: 1)$ LED light source integrated into the LI-6800 measurement chamber $(1 \times 3 \mathrm{~cm})$. The $\mathrm{CO}_{2}$ concentrations flowing into the leaf chamber were controlled at $400 \mu \mathrm{mol} \mathrm{mol}{ }^{-1}$, the temperature of the plant organ in the leaf chamber was maintained at $27^{\circ} \mathrm{C}$, and the relative humidity was $65 \%$. Stems of the third internode were selected to analyze the gas exchange. Before the gas exchange measurements were performed, the diameter of the stems was measured using a 150-mm Vernier caliper (Tricle brand, Shanghai, China) and used to compute the projected area. The total stem surface area was calculated by multiplying the projected area by $\pi$ (3.14). Because the photosynthesis abilities of stems are low, the measurement precision of the device on the stems was much lower than that for the leaves (Figure S1). To collect more reliable data from the stems, we started automatic logging at 3-5 second intervals for 2 min after photosynthesis had reached a relatively steady state. Every measurement of the stems was based on an average of the 2-min recordings. Since PAR was applied to only one side of the stems in the measurement chamber, the photosynthesis rate of stems was expressed on a half-surface area basis. However, because stomata are randomly distributed on the stem surface, the stomatal conductance of stems was expressed on a total surface area basis. For the leaves, the photosynthesis rate was expressed on a regular leaf area basis. Because the leaves of the invasive species have stomata on both the abaxial and adaxial sides, to facilitate comparisons with stems, the stomatal conductance of the leaves was expressed on a double-leaf area basis. The gross photosynthesis rate $\left(P_{\mathrm{g}}\right)$ was subsequently calculated as $P_{\mathrm{n}}+R_{\mathrm{d}}$.

\section{Determination of chlorophyll a fluorescence}

Chlorophyll a fluorescence in the stems and leaves was measured by using a chlorophyll fluorescence imaging (CFI) system (Technologica, UK). Plants were adapted to the dark for 40-50 min, after which the stems of the third internode were detached and placed in the measurement chamber of the CFI system. First, the minimum fluorescence $\left(F_{\mathrm{o}}\right)$ and the maximum fluorescence $(F \mathrm{~m})$ stimulated by a $6000 \mu \mathrm{mol} \mathrm{m}^{-2} \mathrm{~s}^{-1}$ saturating pulse were measured, and the ratio of variable fluorescence to maximum fluorescence $\left(F_{\mathrm{v}} / F_{\mathrm{m}}\right.$, calculated as $1-F_{\mathrm{o}} / F_{\mathrm{m}}$ ), which represents the maximum efficiency of photosystem II (Oxborough \& Baker, 1997), was calculated. Light curves of chlorophyll a fluorescence were measured under the following PAR amounts: 50, 100, 200, 400, 600, 800, 1000 and $1200 \mu \mathrm{mol} \mathrm{m}{ }^{-2} \mathrm{~s}^{-1}$. The stems were adapted for $90 \mathrm{~s}$ at each irradiance, after which the steady fluorescence $(F)$ and maximum fluorescence $(F \mathrm{~m}$ ') in the light-adapted 
state were measured. The effective quantum yield of PSII ( $\Phi_{\text {PSII }}$ ) was calculated as $\Phi_{\text {PSII }}=\Delta F / F_{\mathrm{m}}$ ' $=\left(F_{\mathrm{m}}{ }^{\prime}-F\right) / F_{\mathrm{m}}$ ' (Genty et al., 1989). In addition, the electron transport rate (ETR) was calculated as $\Phi$ $\mathrm{PSII} \times \mathrm{PAR} \times 0.85 \times 0.5$, where the coefficient 0.85 is the PAR absorptivity by plant photosynthetic tissues and where the coefficient 0.5 indicates that the absorbed PAR was equally allocated between PSI and PSII (Krall \& Edwards, 1992).

\section{Determination of photosynthetic and nonphotosynthetic pigment contents}

The procedure for the determination of chlorophyll (Chl) was as follows. Three 2-cm-long stem segments or 10-mm-wide leaf discs were homogenized in $4 \mathrm{~mL}$ of $80 \%$ acetone using a mortar and pestle and then centrifuged at $8000 \mathrm{~g}$ and $4^{\circ} \mathrm{C}$ for $10 \mathrm{~min}$. The contents of Chl $a$, Chl $b$ and the total Chl in the supernatant were determined and calculated according to the methods of Wellburn (1994) and expressed as micrograms per unit area $\left(\mathrm{cm}^{2}\right)$. Since $\mathrm{Chl}$ was mainly distributed on the surface layer of stems, the surface area was used in the calculation of Chl contents.

Anthocyanins in the stems and leaves were extracted with methanol-HCl (99:1, v/v) (Craker et al., 1971). Three 1-cm-long stem segments or 1-cm leaf discs were submerged in $4 \mathrm{~mL}$ of methanol-HCl overnight in the dark. The $\mathrm{Chl}$ in the extract was removed by the addition of $4 \mathrm{~mL}$ of chloroform and $1.5 \mathrm{~mL}$ of deionized water. The absorbance of the anthocyanin extract at $530 \mathrm{~nm}$ was measured. Anthocyanin concentrations were calculated by using a standard curve constructed by cyanidin-3-O-glucoside (5-200 $\mu \mathrm{M})$ and ultimately expressed as micrograms per unit surface area $\left(\mathrm{cm}^{2}\right)$.

\section{Analysis of D1 and Rubisco protein contents}

To extract D1 protein, fresh stems or leaves $(0.3 \mathrm{~g})$ were homogenized in $2 \mathrm{~mL}$ of radioimmunoprecipitation assay (RIPA) buffer containing $1 \mathrm{mM}$ PMSF and the proper amount of protease inhibitor in a precooled mortar, kept in an ice bath for $2 \mathrm{~h}$, and then centrifuged at $12,000 \times \mathrm{g}$ for $10 \mathrm{~min}$ at $4^{\circ} \mathrm{C}$. The supernatant containing D1 protein was temporarily stored at $4^{\circ} \mathrm{C}$. To extract Rubisco, fresh stems or leaves $(0.1 \mathrm{~g})$ were homogenized in $1.5 \mathrm{ml}$ of $60 \mathrm{mM}$ Tris- $\mathrm{HCl}(\mathrm{pH} 7.8)$ buffer consisting of $5 \% \mathrm{PVP}(\mathrm{w} / \mathrm{v}), 0.1 \% \mathrm{NaCl}(\mathrm{w} / \mathrm{v})$ and $2 \%$ glycerol $(\mathrm{v} / \mathrm{v})$ in an ice bath and subsequently centrifuged at $12,000 \times \mathrm{g}$ for $10 \mathrm{~min}$ at $4^{\circ} \mathrm{C}(\mathrm{Zhang}$ et al., 2016). Rubisco proteins were distributed in the supernatant. The proper quantity $(0.1 \mathrm{~mL})$ of the extract of D1 protein or Rubisco and an equal volume of protein loading buffer were mixed together, incubated at $100^{\circ} \mathrm{C}$ for $5 \mathrm{~min}$ and then stored at $4^{\circ} \mathrm{C}$ for further analysis. An aliquot of each sample $(20 \mu \mathrm{l})$ was loaded into one well of an SDS-PAGE gel prepared in advance (Zhang et al., 2016), and the proteins were separated by SDS-PAGE with a Mini-PROTEAN 3 system (Bio-Rad, USA). The separated proteins in the gels were blotted onto PVDF membranes, and the membranes were stained with Ponceau $\mathrm{S}$ to confirm equal protein transfer. The membranes were then washed three times (5 min each) in TBST (50 mM Tris [pH 7.5], $150 \mathrm{mM}$ $\mathrm{NaCl}, 0.1 \%$ Tween 20) and subsequently blocked with $5 \%$ (w/v) nonfat powdered milk in TBST for 1.5 h. The membranes containing then D1 protein and the large subunit of Rubisco were incubated together with PsbA global antibodies (1:10,000 dilution) (Agrisera, Sweden) and anti-Rubisco antibodies (1:1,000 dilution) (Bioss, Beijing, China) overnight at $4^{\circ} \mathrm{C}$. The blots were washed with TBST three times and then incubated with goat anti-rabbit HRP-conjugated secondary antibodies (1:3,000 dilution) at room temperature for 50 min. The blots were subsequently washed three times in TBST, and protein visualization was performed using a Tanon 5200 enhanced chemiluminescence (ECL) detection system (Tanon, Shanghai, China).

\section{Microscopy-based inspection of the stems}

The surface and cross-sectional characteristics of the stems of both the invasive and native species were observed and imaged via a super resolution system (Liyang Precision Machinery, Chengdu, China). To obtain a high resolution image of the surface structure of stems, twenty multi-focus images with shallow depth of field were taken for each stem, and fused into a higher resolution image using the Zerene Stacker software (Zerene Systems LLC, Richland, WA, USA).

\section{Measurement of stomatal aperture}

Main stems of the invasive species were detached between 09:00 and 10:00 h and brought into the lab with the 
cut end submerged in distilled water. Epidermal layer of the stems of the third internode and mature leaves (including adaxial side and abaxial side) of the invasive species were torn off with fine-tipped tweezers, made wet mount microscope slides and viewed using a Leica DM6000 microscope (Leica, Wetzlar, Germany). Digital micrographs of the epidermal surfaces $(20 \times$ and $40 \times$ magnification) were captured and used to quantify stomatal density and stomatal aperture. The image dimensions were calibrated using the objective micrometer. Stomatal densities were analyzed using the images captured through a the 20x objective and expressed on an area basis (stomata $\mathrm{mm}^{-2}$ ). The stomatal density of each sample was calculated as the average of four images that were captured from different fields of view. The stomatal lengths and widths were determined using the images captured through the 40x objective, and for each treatment, at least 20 stomata were measured.

\section{Observations of chloroplast ultrastructure}

Fresh stems of the third internode and mature leaves were cut into approximately $1 \mathrm{mmx} 1 \mathrm{~mm}$ pieces, vacuum infiltrated and fixed in $2.5 \%$ glutaraldehyde and $2 \%$ paraformaldehyde in $0.1 \mathrm{M}$ phosphate buffer $(\mathrm{pH}$ 7.0). The samples were then dehydrated in a graded series of ethanol and embedded in Epon 812 epoxy resin. The embedded samples were sliced into ultrathin sections approximately $70 \mathrm{~nm}$ in thickness using an ultramicrotome (Leica UC7, Leica), double-stained with uranium lead (a $2 \%$ uranyl acetate and lead citrate saturated aqueous solution) and observed under a transmission electron microscope (HT7700, Hitachi Japan). The length and width of the chloroplasts were determined from the images captured at 1200x magnification, and 10 chloroplasts were measured for each treatment.

\section{Statistical analysis of the data}

Statistical significance was determined by one-way ANOVA followed by Duncan post hoc tests using IBM SPSS Statistics 19.0 (IBM, Armonk, NY, USA). The means were considered to be significantly different at the level $P<0.05$ according to the post hoc test. Before performing ANOVA, the data were checked for normality and homogeneity of variance; if the assumptions were not met, the data were log-transformed and retested. Student's test was used to analyze the significance of the changes in stem photosynthesis in the invasive plants after defoliation. The data are presented as the means and standard errors.

\section{Results}

\section{Differences in the plasticity of stem photosynthesis and relevant traits in response to defoliation between $M$. micrantha and native species}

To explore the plasticity of stem photosynthesis in $M$. micrantha, the leaves of $M$. micrantha and three native species (i.e.,Pharbitis nil, Paederia scandens, and Pueraria lobata) were removed. In the control group, no significant differences in net photosynthesis $\left(P_{n}\right)$ and gross photosynthesis $\left(\begin{array}{ll}P \mathrm{~g}\end{array}\right)$ were found between the invasive species and the three native species, although the dark respiration rate $\left(R_{\mathrm{d}}\right)$ of the invasive species was lower than those of the three native species (Figure 1a-c). After defoliation, both $P_{\mathrm{n}}$ and $P_{\mathrm{g}}$ of the invasive species and native species increased significantly, but the $R_{\mathrm{d}}$ remained relatively constant. The increases in $P_{\mathrm{n}}$ and $P_{\mathrm{g}}$ in the invasive species were significantly greater than those in the native species. On day 20 of defoliation, the increase in $P \mathrm{~g}$ $\left(P_{\mathrm{g}}\right)$ intheinvasivespeciesreached $2.4 \mathrm{mmolm}^{-2} \mathrm{~s}^{-1}$, whilethatof thethreenativespeciesreachedonly $0.5 \mathrm{mmolm}^{-2} \mathrm{~s}^{-1}($ Figure $1 \mathrm{~d})$

According to the cross-sections, the stem epidermis of M. micrantha, P. nil, and P. scandens evidently contained anthocyanin pigments, and these pigments disappeared with the removal of leaves (Figure 2a). Though P. lobata did not contain anthocyanins, it had more epidermal pubescence than the other species did, and the epidermal pubescence was not affected by defoliation. In addition to the disappearance of anthocyanin pigments, the 3-4 layers of cells below the stem epidermis of $M$. micrantha became more apparent (indicated by the red arrow). These layers of cells became larger and contained more chlorophyll, which formed a conspicuous green ring zone. However, no similar structural change was found in the native species.

The results of the chlorophyll and chlorophyll a fluorescence measurements showed that there were no 
significant differences in $\mathrm{Chl} a$, Chl $b$, the $\mathrm{Chl} a / b$ ratio and $\mathrm{Fv} / \mathrm{Fm}$ between the invasive species and the native species (Figure 2b-e). However, the invasive species had a greater ETR than the three native species did, especially when the PAR was greater than $400 \mu \mathrm{mol} \mathrm{m} \mathrm{m}^{-2} \mathrm{~s}^{-1}$ (Figure $2 \mathrm{f}-\mathrm{d}$ ). With the removal of leaves, the Chl $a$ content sharply increased in the stems of $M$. micrantha, but the Chl $b$ content remained at a relatively constant state. By contrast, both $\mathrm{Chl} a$ and $\mathrm{Chl} b$ contents showed little change in the native species, except that there was a slight increase in Chl $b$ in $P$. nil. The marked increase in Chl $a$ in the stems of $M$. micrantharesulted in their $\mathrm{Chl} a / b$ ratio being higher than that of the native species. Accompanied by the increases in the Chl acontent and the Chl $a / b$ ratio, the ETR also increased in the invasive species. Thus, the morphology, photosynthetic pigments and photochemistry of the stems in the invasive species were more dynamic than were those of the native species.

Differences in the effects of defoliation on the elongation and survival of stems between the invasive and native species

Under controlled environmental conditions, the average elongation rate of stems of $M$. micrantha was significantly greater than that of $P$. nil and $P$. scandens but was not significantly different from that of $P$. lobata (Figure 3a). With the removal of leaves, the stem elongation rates of all the species decreased by varying degrees, and those of $M$. micrantha were 0.91-9.07 times higher than those of the three native species. On day 30 of defoliation, the survival rate of the $M$. micrantha plants reached $100 \%$, while those of native species ranged from $10 \%-90 \%$ (Figure $3 \mathrm{~b}$ ).

Differences in the survival rate and growth characteristics of the stems between the invasive and native plants in isolated culture.

To further confirm that stem viability of the invasive species was different from that of the native species, their detached stem segments were cultured in petri dishes in a growth chamber (Figure 4). After 20 days of culturing, the survival rates of M. micrantha, P. lobata, P. scandens and P. nil were 100\%, 100\%, 90\% and $11 \%$, respectively (Figure $4 \mathrm{~b}$ ). In isolated culture conditions, $M$. micrantha preferentially developed roots compared with shoots, but the opposite was true for P. lobata and P. scandens. As a result, the length of $M$. micrantha roots was much greater than the length of the roots of the three native species (Figure 4c). Compared with the native species, M. micrantha had a higher ETR than (Figure 4d), which was in agreement with the results observed in the defoliation treatment.

\section{Mechanism governing the upregulation of photosynthesis in stems of invasive species after defoliation}

As described above, the largest upregulation of stem photosynthesis was found in M. micrantha among the four species. To determine the regulatory mechanism governing stem photosynthesis of the invasive species, morphological and physiological changes were further investigated (Figure 5a-1). During the defoliation treatment, the average internode lengths of the stems became shorter, and the average diameter of the stems noticeably decreased (Figure $5 \mathrm{~g}$ ). On day 20 of defoliation, anthocyanins were no longer detected in the stems (Figure 5h). We noted that leaves of $M$. micrantha had stomata on both the adaxial and abaxial surfaces, and the stomatal density (270) on the abaxial surface was 5 times that on the adaxial surface. The density of stomata on the surface of stems was comparable to that on the adaxial surface of the leaves (Figure 5i). However, the stomata on the stems were evidently larger than those on the leaves. The stomatal density of the stems was not influenced by the defoliation treatment, whereas the stomatal aperture and stomatal conductance increased significantly (Figure 5i-l). The width of the stomata on the stems of defoliated plants was even larger than that on either the adaxial surface or abaxial surface of the leaves of the control plants. However, the stomatal conductance of stems of the defoliated plants was still significantly lower than that of the leaves because the leaves had a greater average stomatal density.

Under normal conditions, the total chlorophyll (Chl) content per unit area (Chl $a+b)$ and the Chl $a / b$ ratio in the stems were equal to a quarter and a half of those in the leaves, respectively (Figure 6a-b). In addition, the soluble sugar content in the stems was also significantly lower than that in the leaves (Figure $6 \mathrm{c})$. With the removal of leaves, both the total Chl content the Chl $a / b$ ratio gradually increased in the 
stems; however, the soluble sugar level showed a decreasing trend. On day 10 of defoliation, the differences in total $\mathrm{Chl}$ in the stems between the treatment group and control group had reached a significant level. Though the total $\mathrm{Chl}$ content continued to increase in the stems of defoliated plants during the following 20 days, it was consistently lower than that in the leaves of the control plants. By contrast, the Chl a/b ratio of the stems of the defoliated plants was found to exceed that of leaves on day 20 of defoliation. In fact, photosynthesis of the stems responded to defoliation much faster than the chlorophyll and soluble sugar contents did. On day 3 of defoliation, the gross photosynthesis rate of the stems was greater than that of the control plants and continued to increase during the next several days (Figure 6d-e). The ETR also significantly increased in the stems 20 days after defoliation, reaching a level that was equal to that of leaves (Figure 6f). In addition, the D1 protein (PsbA) of PSII was dramatically upregulated in the stems, and its concentration even exceeded that in the leaves, but the RbcL protein content appeared to decrease (inserted in Figure 6f). Therefore, the increase in stem photosynthesis of $M$. micrantha was due to multiple factors that improved the gas exchange efficiency of the stems and the ability of chloroplasts to absorb light energy.

Ultrastructural observations revealed that the chloroplasts in the stems and leaves of M. micrantha were elliptical shaped and contained 1-2 starch grains (Figure 7a-f). The starch grains occupied more than 50\% of the interior space of the leaf chloroplasts, but those that accumulated in the stem chloroplasts were much smaller. Defoliation significantly affected the structure of the stem chloroplasts. The longitudinal section of the chloroplasts changed from being elliptical shaped to spindle shaped. As the length increased by $72.5 \%$ and the width decreased by $15.2 \%$, the length/width ratio of the chloroplasts in the defoliated plants was approximately 2-fold that of the control plants (Figure 7g-i). Such changes might increase the light-reception area of the chloroplasts. In addition to the change in shape, the number and size of plastoglobuli in the stem chloroplasts of defoliated plants were also larger than those in the intact plants, the diameter of the former reached $0.44 \mu \mathrm{m}$.

\section{Discussion}

\section{Effects of stem physiological plasticity on the growth}

\section{of Mikania micrantha}

Understanding the ecophysiological mechanisms underlying species invasion is required to perform effective management. Morphological and physiological plasticity associated with the broad expansion of various invasive species has been verified by a large number of empirical studies (Richards et al. , 2006; Riis et al. , 2010; Geng et al. , 2016). For invasive vines, morphological plasticity of internode length and internode number of the stems may allow these plants to actively occupy favorable microhabitats, ultimately affecting plant fitness (Schweitzer \& Larson, 1999). However, little is known about the physiological plasticity of stems in invasive vine species.

In addition to leaves, nonfoliar organs such as stems, bark, and fruits of many higher plants can also carry out photosynthesis (Xu et al., 1997; Tarvainen et al., 2018). Although the photosynthesis ability of nonfoliar organs is often significantly less than that of leaves, it still plays an important physiological role in the growth, development and stress resistance of plants. For example, stem photosynthesis can increase stem growth (Cernusak \& Hutley, 2011; Steppe et al., 2015), improve the carbon economy of whole plants (Nilsen, 1995) and improve drought resistance (Vandegehuchte et al., 2015). In this study, we used a gas exchange analysis technique to confirm that the stems of $M$. micrantha and native species were able to perform photosynthesis because dramatically more $\mathrm{CO}_{2}$ was released from the stems in the dark than in the light (Figure $\mathrm{S} 1$ ). Our results also revealed that the stem cortex of the vine species was permeable to $\mathrm{CO}_{2}$. This is unlike that in woody species, as the cambium in the stems of these species is gas impermeable and blocks radial $\mathrm{CO}_{2}$ diffusion (Steppe et al., 2007). As a result, stem photosynthesis in woody species can be used only to refix respired $\mathrm{CO}_{2}$, but in vine species, stem photosynthesis can fix $\mathrm{CO}_{2}$ from both cellular respiration and ambient air. In evolutionary terms, stem photosynthesis in vine species is much more similar to leaf photosynthesis than that in woody species.

Stem photosynthesis ability and its impact on fitness vary from species to species (Berveiller et al., 2007). 
In the current study, compared with the three native species, M. micrantha manifested a greater plasticity of stem photosynthesis, as reflected by changes in the net photosynthesis rate, total photosynthesis rate, chlorophyll a content, and ETR during defoliation (Figure 1-2). Related to these physiological characteristics, compared with the three native species, M. micrantha demonstrated a higher stem elongation rate during the leaf defoliation treatment (Figure 3). Moreover, the survival rate of the defoliated M. micrantha plants reached $100 \%$, while the rates of the native species ranged from $10 \%-90 \%$, suggesting that physiological plasticity of the stems plays an important role in maintaining the survival and growth of $M$. micrantha under defoliation. Similarly, under the conditions of isolated culture, M. micrantha showed higher stem photosynthesis than did the native species, as indicated by the ETR (Figure 4). As a result, the survival rate of $M$. micrantha stem segments was $100 \%$, which was higher than that of two of the three native species. We noted that the stem segment-regeneration strategy adopted by $M$. micrantha was different from that adopted by the native species (Figure 4). M. micrantha preferentially rooted first, whereas the native species $P$. lobata and $P$. scandens tended to grow leaves first; moreover, $P$. nil segments could hardly regenerate. This may also be associated with stem photosynthesis performance. Compared with those of the native species, the stem segments of $M$. micrantha, which a higher photosynthesis rate, produced more carbohydrates, setting the stage for the isolated stems of $M$. micrantha to root first. The growth of roots allows the regenerated plants to rapidly uptake water and nutrients, thereby increasing the probability of survival. In contrast, the photosynthesis ability of the stems of the native species was lower, so prioritizing the growth of only new leaves as photosynthetic organs can guarantee supplies of carbohydrates for further growth of the regenerated plants.

In summary, high plasticity of stem photosynthesis improves the survival and fitness of M. micrantha compared with native species under harsh conditions and allows the plants to rapidly recover from defoliation injuries. Many invasive alien plants can be controlled by releasing enemy insects to attack their leaves (Clewley et al., 2012; Havens et al., 2019). This technique may not be effective to manage M. micrantha, as this invasive species can enhance its stem photosynthesis to compensate for the decrease in leaf photosynthesis to some extent. Our results show that physiological phenotypic plasticity promotes the invasion success of alien vine plant invaders.

\section{Modified mechanism of stem photosynthesis in M. micrantha}

Plants obtain carbohydrates from photosynthesis and consume them via respiratory processes for maintaining metabolism (McDowell \& Sevanto, 2010). The removal of leaves stops the primary carbohydrate source from plants, causing them to experience carbon stress. Defoliation-induced carbon stress can reduce nonstructural carbohydrate reserves and increase both vulnerability to insect infestation and hydraulic performance (Anderegg \& Callaway, 2012). However, in some cases, a reduction in leaf photosynthesis can be compensated for by the mobilization of stored carbohydrates, reallocation of carbon or stem photosynthesis (Eyles et al., 2009). Compared with leaf photosynthesis, stem photosynthesis is less vulnerable to environmental stresses such as seasonal changes and reduced water availability; therefore, stem photosynthesis is able to compensate for the loss of leaf photosynthesis under stress conditions (Nilsen \& Bao, 1990; Nilsen et al., 1993). In $M$. micrantha, the response of soluble sugars to defoliation treatment was slower than the response of stem photosynthesis (Figure 6), suggesting that stem photosynthesis rather than the use of stored carbohydrates is preferentially used to compensate for the decrease in leaf photosynthesis.

The carbon starvation-induced optimization of stem photosynthesis ability in M. micrantha is an integration of a series of interactive factors. In terms of the phenotype, removal of the leaves decreased the internode length, diameter and anthocyanin pigmentation of the stems (Figure 5). Although internode length is unrelated to stem photosynthesis ability, a shorter internode length could provide more opportunities for sprouting new leaves along the stems. By contrast, thinner stems have a larger surface area-to-volume ratio that favors gas exchange between the stems and external environment. From this perspective, stems with a smaller diameter could promote stem photosynthesis. However, as the low projected area of thin stems may affect their light capture ability. Interestingly, this deleterious effect could be offset by reducing the amount of anthocyanin pigments, which act as light barriers, in the stem epidermis. 
Anthocyanin pigments can act as light attenuators or as antioxidants to protect the photosynthetic apparatus in plant vegetative tissues (Neill \& Gould, 2003). Since anthocyanins were distributed in the epidermis of the stems of the plants in the present study, they were more likely to play a light-barrier role rather than an antioxidant role. In fact, anthocyanins accumulate in young stems but diminish with maturity. This pigmentation pattern has a lot in common with that in leaves (Hughes et al. , 2007; Zhu et al. , 2018), suggesting that different kinds of tissues can utilize the same approach to protect immature photosynthetic apparatuses. With regard to the native species, $P$. nil and $P$. scandens had the same pigmentation pattern in their stems as $M$. micrantha did (Figure 2 and S2). The stems of $P$. lobata did not accumulate anthocyanins, but they were more pubescent than the stems of the other species were. Pubescence can play a similar role as anthocyanins with regard to photoprotection (Liakopoulos et al. , 2006). Defoliation induced an improvement in the stem photosynthesis ability, allowing the apparatuses to withstand stronger irradiance. In this case, anthocyanins become an unnecessary tool to protect the stem photosynthetic apparatus. After removal of the leaves, the reduction in anthocyanins in the stems was observed to be associated with decreased soluble sugar contents, indicating that sugars are involved in the regulation of anthocyanins. This is consistent with the findings of a recent study showing the regulatory mechanism of anthocyanins in kiwifruit (Nardozza et al., 2020).

In addition to the removal of light-barrier pigments, carbon starvation also induced stomatal opening and thereby removed the obstacle that limited gas exchange between the stems and the atmosphere. Stomatal opening was confirmed by microscopy-based observations and measurements of stomatal conductance based on $\mathrm{H}_{2} \mathrm{O}$ exchange (Figure 5). However, because the stomatal densities were different, stomatal conductance in the stems without leaves was observed still to be lower than that in the leaves of the plants in the normal-growth group.

In addition to overcoming the barriers to light and $\mathrm{CO}_{2}, M$. micrantha was also able to optimize its cellular and subcellular structure to increase photosynthesis efficiency. There were 3-4 layers of cells below the epidermis that became larger and accumulated increased amounts of chlorophyll, indicating that photosynthesis was mainly performed in this zone of the stems (Figure 2). Ultrastructural observations showed that chloroplasts in this zone in the plants in normal-growth group were elliptica -shaped; however, after the removal of their leaves, they became spindle shaped, and their length dramatically increased (Figure 7). Such changes might increase the light-receiving area of the chloroplasts. The modification of both the Chl $a / b$ ratio and plastoglobule size and the enhanced turnover of D1 protein supported that chloroplasts were exposed to high light in the stems of the defoliated plants.

Plastoglobuli are lipoprotein particles present in both nonphotosynthetic and photosynthetic plastids in plants (van Wijk \& Kessler, 2017). In chloroplasts, they play functional roles in chloroplast biogenesis, redox and photosynthetic regulation and senescence by exchanging metabolites with the thylakoid membrane (Vom Dorp et al. , 2015). They can serve as extrathylakoid storage sites for excess isoprenoid lipids, such as $\alpha$ tocopherol (vitamin E), plastoquinone-9, and traces of xanthophylls (Lichtenthaler, 2007). Under high-light conditions, as the essential components of thylakoids, $\alpha$-tocopherol and plastoquinone- 9 often accumulate in excess amounts in chloroplasts and are stored in plastoglobuli. The degradation of epidermal anthocyanins and changes in chloroplast shape caused the chloroplasts in the stem tissues to be exposed to high light. This could explain why, compared with those of intact plants, the chloroplasts in the stems of the defoliated plants had a higher number and a larger size of plastoglobuli (Figure 7).

During defoliation, the Chl a content increased rapidly in the stems of $M$. micrantha, whereas the Chl $b$ content was maintained at a similar level (Figure 2). As a consequence, the Chl $a / b$ ratio dramatically increased, which is in agreement with the findings in leaves exposed to high irradiance (Kitajima \& Hogan, 2003; Sarijeva et al. , 2007). The differences in Chl $a$ / $b$ ratios between sun and shade leaves are due to the high-irradiance-adaptation response of the photosynthetic machinery of sun leaves, which have a much lower quantity of light-harvesting Chl $a / b$ proteins (LHCII) and a greater number of PSII cores than shade leaves do (Lichtenthaler et al., 1982). Since the Chl $a / b$ ratio was found to be positively correlated with the ratio of PSII cores to LHCII (Terashima \& Hikosaka, 1995), this ratio is used as an indicator of N partitioning within 
a leaf (Kitajima \& Hogan, 2003). It is likely that the stems experienced N limitation during defoliation, as the removal of leaves caused energy starvation in the roots, which could in turn reduce the uptake of N. If so, the adjustment of the stem $\mathrm{Chl} a / b$ ratio during the removal of leaves was a result of irradiance and $\mathrm{N}$ availability acting together. In fact, differences in $\mathrm{N}$ partitioning in stem chloroplasts between defoliated plants and intact plants could be confirmed by the fact that the stems of the defoliated plants had more D1 protein and a lower amount of soluble protein than the stems of the control plants did (Figure 6) Moreover, the Rubisco content in the defoliated stems also seemed to be slightly reduced compared with that in the stems of intact plants.

The photosynthesis of plants depends on the function of photosystem II (PSII), which is a large multisubunit protein complex integrated within the thylakoid membrane (Andersson and Barber, 1994). The PSII reaction center contains the homologous D1 and D2 proteins, PsbI, PsbW and cytochrome b559. This study showed that the amount of D1 protein dramatically increased in the stems of $M$. micrantha after removal of the leaves (Figure 6). The increase in D1 protein was positively associated with the Chl $a / b$ ratio, the ETR and $\Phi$ PSII (Figure S3), indicating that more PSII reaction centers were assembled in the stem chloroplasts during defoliation. However, the increase in D1 protein relative to that of the control was evidently greater than the increase in total $\mathrm{Chl}$ and the $\mathrm{Chl} a / b$ ratio. In fact, the D1 protein in PS II is prone to irreversible damage caused by reactive oxygen species that are formed in the light, and there is an intricate repair mechanism involving degradation of the damaged D1 reaction center protein and insertion of the newly synthesized copy into the photosystem for maintaining photosynthesis (Lindahl et al., 2000). Generally, the rate of D1 impairment does not exceed the rate of its repair under optimal growth conditions; therefore, no adverse effects on photosynthesis efficiency are manifested. Stress conditions such as high light can disrupt the balance between D1 protein impairment and its repair, resulting in photoinhibition and lowering the quantum yield of photosynthesis and the ETR of PSII (Andersson \& Aro, 2006). Thus, D1 protein turnover is crucial for plasticity of the photosynthetic apparatus. In the stems of $M$. micrantha, the high rate of D1 synthesis guaranteed the maintenance of high photosynthesis efficiency in the absence of anthocyaninmediated photoprotection.

We demonstrate here that chloroplast morphology, anthocyanins, stomata, photosynthetic pigments and photosynthesis-related proteins are involved in improving the photosynthesis efficiency of the stems of $M$. micrantha during defoliation. However, the details through which such processes occur are far from clear. The regulatory mechanisms underlying anthocyanin degradation and stomatal behavior in the stems need to be investigated. Moreover, the mechanism through which $\mathrm{N}$ partitioning between thylakoid membrane proteins and soluble proteins contributes to improved photosynthesis efficiency should be clarified.

\section{Acknowledgements}

The work was funded by the National Natural Science Foundation of China (31870374; 32001924), the National Key Research and Development Program of China (2017YFC1200105) and the Science and Technology Planning Project of Guangdong Province (2019B121201003).

\section{Conflict of Interest}

The authors declare no conflict of interest.

\section{Author contributions}

JZ and T-JZ conceived the idea, designed the experiment and wrote the manuscript. JZ, B-HL and WJL carried out the morphological and physiological analyses. Q-LZ and M-LC conducted the western blot analyses, C-LP coordinated the project and revised the manuscript.

\section{References}

Anderegg, W. R. \& Callaway, E. S. (2012). Infestation and hydraulic consequences of induced carbon starvation. Plant physiology, 159(4), 1866-1874. 
Andersson, B. \& Aro, E.-M. (2006). Photodamage and D1 Protein Turnover in Photosystem II. Regulation of Photosynthesis , 11, 377.

Andersson, B., \& Barber, J. (1994). Composition, organization, and dynamics of thylakoid membranes Advances in molecular and cell biology (Vol. 10, pp. 1-53): Elsevier.

Ávila, E., Herrera, A. \& Tezara, W. (2014). Contribution of stem $\mathrm{CO}_{2}$ fixation to whole-plant carbon balance in nonsucculent species. Photosynthetica , 52(1), 3-15.

Ávila-Lovera, E., \& Tezara, W. (2018). Water-use efficiency is higher in green stems than in leaves of a tropical tree species. Trees, 32(6), 1547-1558.

Berveiller, D., Kierzkowski, D. \& Damesin, C. (2007). Interspecific variability of stem photosynthesis among tree species. Tree physiology , 27(1), 53-61.

Bloemen, J., Vergeynst, L. L., Overlaet-Michiels, L. \& Steppe, K. (2016). How important is woody tissue photosynthesis in poplar during drought stress? Trees , 30(1), 63-72.

Bossard, C. C. \& Rejmanek, M. (1992). Why have green stems? Functional ecology , 6(2), 197-205.

Cernusak, L. A. \& Cheesman, A. W. (2015). The benefits of recycling: how photosynthetic bark can increase drought tolerance. New Phytologist, 208, 995-997.

Cernusak, L. A. \& Hutley, L. B. (2011). Stable isotopes reveal the contribution of corticular photosynthesis to growth in branches ofEucalyptus miniata. Plant Physiology , 155(1), 515-523.

Chen, B.-M., Peng, S.-L. \& Ni, G.-Y. (2009). Effects of the invasive plant Mikania micrantha HBK on soil nitrogen availability through allelopathy in South China. Biological Invasions , 11(6), 1291-1299.

Clewley, G. D., Eschen, R., Shaw, R. H. \& Wright, D. J. (2012). The effectiveness of classical biological control of invasive plants. Journal of Applied Ecology , 49(6), 1287-1295.

Courchamp, F., Fournier, A., Bellard, C., Bertelsmeier, C., Bonnaud, E., Jeschke, J. M. \& Russell, J. C. (2017). Invasion biology: specific problems and possible solutions. Trends in Ecology 8 Evolution , 32(1), $13-22$.

Craker, L., Standley, L. \& Starbuck, M. (1971). Ethylene control of anthocyanin synthesis in sorghum. Plant Physiology , 48(3), 349-352.

Day, M. D., Clements, D. R., Gile, C., Senaratne, W. K., Shen, S., Weston, L. A. \& Zhang, F. (2016). Biology and impacts of pacific islands invasive species. 13. Mikania micrantha Kunth (Asteraceae) 1. Pacific Science , 70(3), 257-285.

De Baerdemaeker, N. J., Salomón, R. L., De Roo, L. \& Steppe, K. (2017). Sugars from woody tissue photosynthesis reduce xylem vulnerability to cavitation. New Phytologist , 216(3), 720-727.

Eyles, A., Pinkard, E. A., O'GRADY, A. P., Worledge, D. \& Warren, C. R. (2009). Role of corticular photosynthesis following defoliation inEucalyptus globulus . Plant, Cell E Environment, 32(8), 1004-1014.

Gao, J., Zhou, J., Sun, Z., Niu, J., Zhou, C., Gu, D., Huang, Y. \& Zhao, P. (2016). Suppression of nighttime sap flux with lower stem photosynthesis in Eucalyptus trees. International Journal of Biometeorology, 60(4), $545-556$.

Geng, Y., van Klinken, R. D., Sosa, A., Li, B., Chen, J. \& Xu, C.-Y. (2016). The relative importance of genetic diversity and phenotypic plasticity in determining invasion success of a clonal weed in the USA and China. Frontiers in Plant Science, 7, 213.

Genty, B., Briantais, J.-M. \& Baker, N. R. (1989). The relationship between the quantum yield of photosynthetic electron transport and quenching of chlorophyll fluorescence. Biochimica et Biophysica Acta-General Subjects, 990(1), 87-92. 
Havens, K., Jolls, C. L., Knight, T. M. \& Vitt, P. (2019). Risks and rewards: Assessing the effectiveness and safety of classical invasive plant biocontrol by arthropods. BioScience, 69(4), 247-258.

Holm, L. G., Plucknett, D. L., Pancho, J. V. \& Herberger, J. P. (1977). The world's worst weeds. Distribution and biology : University press of Hawaii.

Hughes, N. M., Morley, C. B. \& Smith, W. K. (2007). Coordination of anthocyanin decline and photosynthetic maturation in juvenile leaves of three deciduous tree species. New Phytologist , 175(4), 675-685.

Keser, L. H., Dawson, W., Song, Y.-B., Yu, F.-H., Fischer, M., Dong, M. \& van Kleunen, M. (2014). Invasive clonal plant species have a greater root-foraging plasticity than non-invasive ones. Oecologia , 174(3), 10551064 .

Kitajima, K. \& Hogan, K. P. (2003). Increases of chlorophyll a/b ratios during acclimation of tropical woody seedlings to nitrogen limitation and high light. Plant, Cell $\& 3$ Environment, 26(6), 857-865.

Kocurek, M., Kornas, A., Wierzchnicki, R., Luettge, U. \& Miszalski, Z. (2020). Importance of stem photosynthesis in plant carbon allocation of Clusia minor. Tree , 34, 1009-1020.

Krall, J. P. \& Edwards, G. E. (1992). Relationship between photosystem II activity and $\mathrm{CO}_{2}$ fixation in leaves.Physiologia Plantarum, 86(1), 180-187.

Li, M., Lu, E., Guo, Q., Zan, Q., Wei, P., Jiang, L., Xu, H. \& Zhong, T. (2012). Evaluation of the controlling methods and strategies for Mikania micrantha H. B. K. Acta Ecologica Sinica , 32(10), 3240-3251.

Li, W.-H., Zhang, C.-B., Jiang, H.-B., Xin, G.-R., \& Yang, Z.-Y. (2006). Changes in soil microbial community associated with invasion of the exotic weed, Mikania micrantha HBK. Plant and soil , 281(1-2), 309-324.

Liakopoulos, G., Nikolopoulos, D., Klouvatou, A., Vekkos, K.-A., Manetas, Y., \& Karabourniotis, G. (2006). The photoprotective role of epidermal anthocyanins and surface pubescence in young leaves of grapevine (Vitis vinifera ). Annals of Botany, 98(1), 257-265.

Lichtenthaler, H. K. (2007). Biosynthesis, accumulation and emission of carotenoids, $\alpha$-tocopherol, plastoquinone, and isoprene in leaves under high photosynthetic irradiance. Photosynthesis Research, 92(2), 163-179.

Lichtenthaler, H. K., Kuhn, G., Prenzel, U. \& Meier, D. (1982). Chlorophyll-protein levels and degree of thylakoid stacking in radish chloroplasts from high-light, low-light and bentazon-treated plants.Physiologia Plantarum, 56(2), 183-188.

Lindahl, M., Spetea, C., Hundal, T., Oppenheim, A. B., Adam, Z. \& Andersson, B. (2000). The thylakoid FtsH protease plays a role in the light-induced turnover of the photosystem II D1 protein. The Plant Cell, 12(3), 419-431.

Liu, B., Yan, J., Li, W., Yin, L., Li, P., Yu, H., Xing L, Cai, M., Wang, H., Zhao, M., Zheng, J., Sun, F., Wang, Z., Jiang, Z., Ou, Q., Li, S., Qu, L., Zhang, Q., Zheng, Y., Qiao, X., Xi, Y., Zhang, Y., Jiang, F., Huang, C., Liu, C., Ren, Y., Wang, S., Liu, H., Guo, J., Wang, H., Dong, H., Peng, C., Qian, W. \& Fan, W. (2020). Mikania micrantha genome provides insights into the molecular mechanism of rapid growth. Nature communications, 11,340 .

Lowe, S., Browne, M., Boudjelas, S. \& DePoorter, M. (2001). 100 of the world's worst invasive alien species, a selection from the Global Invasive Species Database. IUCN-ISSG (Invasive Species Specialist Group), Auckland, New Zealand.

Mack, R. N., Simberloff, D., Mark Lonsdale, W., Evans, H., Clout, M. \& Bazzaz, F. A. (2000). Biotic invasions: causes, epidemiology, global consequences, and control. Ecological Applications , 10(3), 689-710.

Manrique, V., Diaz, R., Cuda, J. P. \& Overholt, W. A. (2011). Suitability of a new plant invader as a target for biological control in Florida. Invasive Plant Science and Management , 4(1), 1-10. 
McDowell, N. G. \& Sevanto, S. (2010). The mechanisms of carbon starvation: how, when, or does it even occur at all? The New Phytologist, 186(2), 264-266.

Nardozza, S., Boldingh, H. L., Kashuba, M. P., Feil, R., Jones, D., Thrimawithana, A. H., Ireland, H. S., Philippe, M., Wohlers, M. W. \& McGhie, T. K. (2020). Carbon starvation reduces carbohydrate and anthocyanin accumulation in red-fleshed fruit via trehalose 6-phosphate and MYB27. Plant, Cell \& Environment, 43(4), 819-835.

Neill, S. O. \& Gould, K. S. (2003). Anthocyanins in leaves: light attenuators or antioxidants? Functional Plant Biology , 30(8), 865-873.

Nilsen, E. T. \& Bao, Y. (1990). The influence of water stress on stem and leaf photosynthesis in Glycine max and Sparteum junceum (Leguminosae). American Journal of Botany , 77(8), 1007-1015.

Nilsen, E. T. (1995). Stem photosynthesis: extent, patterns, and role in plant carbon economy Plant Stems (pp. 223-240): Elsevier.

Nilsen, E. T., Karpa, D., Mooney, H. \& Field, C. (1993). Patterns of stem photosynthesis in two invasive legumes (Spartium junceum, Cytisus scoparius) of the California coastal region. American Journal of Botany , 80(10), 1126-1136.

Nivot, N., Olivier, A. \& Lapointe, L. (2008). Vegetative propagation of five northern forest understory plant species from either rhizome or stem sections. HortScience, 43(5), 1531-1537.

Oxborough, K. \& Baker, N. R. (1997). Resolving chlorophyll a fluorescence images of photosynthetic efficiency into photochemical and non-photochemical components-calculation of qP and Fv'/Fm'; without measuring Fo. Photosynthesis Research , 54(2), 135-142.

Pate, J. \& Jeschke, W. (1995). Role of stems in transport, storage, and circulation of ions and metabolites by the whole plant. Plant Stems: Physiology and Functional Morphology (pp. 177-204): Academic Press.

Pfanz, H. \& Aschan, G. (2001). The existence of bark and stem photosynthesis in woody plants and its significance for the overall carbon gain. An Eco-physiological and Ecological Approach Progress in Bbotany (pp. 477-510): Springer.

Pfanz, H., Aschan, G., Langenfeld-Heyser, R., Wittmann, C. \& Loose, M. (2002). Ecology and ecophysiology of tree stems: corticular and wood photosynthesis. Naturwissenschaften , 89(4), 147-162.

Pigliucci, M. (2001). Phenotypic plasticity: beyond nature and nurture: Johns Hopkins University Press.

Ren, M. X. \& Zhang, Q. G. (2009). The relative generality of plant invasion mechanisms and predicting future invasive plants. Weed Research , 49(5), 449-460.

Richards, C. L., Bossdorf, O., Muth, N. Z., Gurevitch, J. \& Pigliucci, M. (2006). Jack of all trades, master of some? On the role of phenotypic plasticity in plant invasions. Ecology letters, 9(8), 981-993.

Riis, T., Lambertini, C., Olesen, B., Clayton, J. S., Brix, H. \& Sorrell, B. K. (2010). Invasion strategies in clonal aquatic plants: are phenotypic differences caused by phenotypic plasticity or local adaptation? Annals of Botany, 106(5), 813-822.

Sarijeva, G., Knapp, M. \& Lichtenthaler, H. K. (2007). Differences in photosynthetic activity, chlorophyll and carotenoid levels, and in chlorophyll fluorescence parameters in green sun and shade leaves of Ginkgo and Fagus. Journal of Plant Physiology , 164(7), 950-955.

Schmitz, N., Egerton, J., Lovelock, C., \& Ball, M. (2012). Light-dependent maintenance of hydraulic function in mangrove branches: do xylary chloroplasts play a role in embolism repair? New Phytologist, 195(1), 40-46.

Schweitzer, J. A., \& Larson, K. C. (1999). Greater morphological plasticity of exotic honeysuckle species may make them better invaders than native species. Journal of the Torrey Botanical Society, 15-23. 
Sevanto, S., Mcdowell, N. G., Dickman, L. T., Pangle, R. \& Pockman, W. T. (2014). How do trees die? A test of the hydraulic failure and carbon starvation hypotheses. Plant, Cell \& Environment, 37(1), 153-161.

Steppe, K., Saveyn, A., McGuire, M. A., Lemeur, R. \& Teskey, R. O. (2007). Resistance to radial $\mathrm{CO}_{2}$ diffusion contributes to between-tree variation in $\mathrm{CO}_{2}$ efflux of Populus deltoides stems. Functional Plant Biology , 34(9), 785-792.

Steppe, K., Sterck, F. \& Deslauriers, A. (2015). Diel growth dynamics in tree stems: linking anatomy and ecophysiology. Trends in Plant Science, 20(6), 335-343.

Tarvainen, L., Wallin, G., Lim, H., Linder, S., Oren, R., Ottosson Löfvenius, M., Räntfors, M., Tor-Ngern, P. \& Marshall, J. (2018). Photosynthetic refixation varies along the stem and reduces $\mathrm{CO}_{2}$ efflux in mature boreal Pinus sylvestristrees. Tree physiology , 38(4), 558-569.

Terashima, I. \& Hikosaka, K. (1995). Comparative ecophysiology of leaf and canopy photosynthesis. Plant, Cell \& Environment, 18(10), 1111-1128.

van Wijk, K. J. \& Kessler, F. (2017). Plastoglobuli: plastid microcompartments with integrated functions in metabolism, plastid developmental transitions, and environmental adaptation. Annual Review of Plant Biology , 68, 253-289.

Vandegehuchte, M. W., Bloemen, J., Vergeynst, L. L. \& Steppe, K. (2015). Woody tissue photosynthesis in trees: salve on the wounds of drought? New Phytologist , 208(4), 998-1002.

Violle, C., Garnier, E., Lecoeur, J., Roumet, C., Podeur, C., Blanchard, A. \& Navas, M.-L. (2009). Competition, traits and resource depletion in plant communities. Oecologia , 160(4), 747-755.

Vitousek, P. M., D'Antonio, C. M., Loope, L. L. \& Westbrooks, R. (1996). Biological invasions as global environmental change.American Scientist , 84(5), 468-479.

Vom Dorp, K., Hölzl, G., Plohmann, C., Eisenhut, M., Abraham, M., Weber, A. P., Hanson, AD. \& Dörmann, P. (2015). Remobilization of phytol from chlorophyll degradation is essential for tocopherol synthesis and growth of Arabidopsis. The Plant Cell , 27(10), 2846-2859.

Wang, B., Liao, W., Zan, Q., Li, M., Zhou, X. \& Gao, S. (2003). The spreads of Mikania micrantha in China. Acta Scientiarum Naturalium Universitatis Sunyatseni , 42(47-50), 54.

Waterhouse, B. (2003). Know your enemy: recent records of potentially serious weeds in northern Australia, Papua New Guinea and Papua (Indonesia). Telopea, 10(1), 477-485.

Wellburn, A. R. (1994). The spectral determination of chlorophylls a and b, as well as total carotenoids, using various solvents with spectrophotometers of different resolution. Journal of Plant Physiology , 144(3), 307-313.

Wittmann, C. \& Pfanz, H. (2014). Bark and woody tissue photosynthesis: a means to avoid hypoxia or anoxia in developing stem tissues. Functional Plant Biology , 41(9), 940-953.

Xu, H.-L., Gauthier, L., Desjardins, Y. \& Gosselin, A. (1997). Photosynthesis in leaves, fruits, stem and petioles of greenhouse-grown tomato plants. Photosynthetica , 33(1), 113-123.

Zenni, R. D., Lamy, J.-B., Lamarque, L. J. \& Porté, A. J. (2014). Adaptive evolution and phenotypic plasticity during naturalization and spread of invasive species: implications for tree invasion biology.Biological Invasions , 16(3), 635-644.

Zhang, L., Ye, W., Cao, H. \& Feng, H. (2004). Mikania micranthaHBK in China-an overview. Weed Research, $44(1), 42-49$.

Zhang, T.-J., Chow, W. S., Liu, X.-T., Zhang, P., Liu, N. \& Peng, C.-L. (2016). A magic red coat on the surface of young leaves: anthocyanins distributed in trichome layer protect Castanopsis fissa leaves from photoinhibition. Tree physiology, 36(10), 1296-1306. 
Zhu, H., Zhang, T.-J., Zheng, J., Huang, X.-D., Yu, Z.-C., Peng, C.-L. \& Chow, W. (2018). Anthocyanins function as a light attenuator to compensate for insufficient photoprotection mediated by nonphotochemical quenching in young leaves of Acmena acuminatissima in winter.Photosynthetica , 56(1), 445-454.

\section{Figure legend}

Figure 1. Photosynthetic characteristics in stems of invasive plantMikania micrantha and three native plants on 20 days after defoliation. (a) Net photosynthesis at PPFD of $800 \mu \mathrm{mol} \mathrm{m} \mathrm{m}^{-2} \mathrm{~s}^{-1}$. (b) Day respiration. (c) Gross photosynthesis. (d) The increase of gross photosynthesis in the defoliation group relative to control group. Different letters above bars indicate statistical significance $(P<0.05)$. Abbreviations: Mm, Mikania micrantha ; Pn, Pharbitis nil ; Ps, Paederia scandens ; $\mathrm{Pl}$, Pueraria lobata $; P_{\mathrm{n}}$, net photosynthesis; $R_{\mathrm{d}}$, day respiration; $P_{\mathrm{g}}$, gross photosynthesis. $P_{\mathrm{g}}$, thedifferenceof $P_{\mathrm{g}}$ betweenthedefoliatedplantsandnormallygrowthplants.

Figure 2. Chlorophyll contents, Fv/Fm and ETR in stems of invasive plantMikania micrantha and three native plants on 20 days after defoliation. (a) Transverse section of the stems. (b-d) Chlorophyll $a, b$ and $a / b$ ratio. (e) Maximal quantum yield. (f) Light response curve of electron transport rate. (g) Electron transport rate at PPFD of $1200 \mu \mathrm{mol} \mathrm{m} \mathrm{m}^{-2} \mathrm{~s}^{-1}$. Different letters above bars indicate statistical significance $(P$ $<0.05)$. Abbreviations: Mm, Mikania micrantha; Pn, Pharbitis nil ; Ps, Paederia scandens ; Pl, Pueraria lobata ; Fv/Fm, maximal quantum yield; ETR, electron transport rate; PPFD, photosynthetic photon flux density.

Figure 3. Growth rate (a) in stems of invasive plant Mikania micrantha and three native plants after defoliation and the survival rate (b) on 30 days after defoliation. Abbreviations: Mm, Mikania micrantha; Pn, Pharbitis nil ; Ps, Paederia scandens ; Pl,

Pueraria lobata.

Figure 4. Survival rate, root length and ETR in stems of invasive plantMikania micrantha and three native plants after isolated culture for 20 days. Abbreviations: ETR, electron transport rate; Mm, Mikania micrantha ; Pn, Pharbitis nil ; Ps, Paederia scandens ; Pl, Pueraria lobata.

Figure 5. Change of morphology and stomatal behavior in stems of Mikania micrantha at day 20 of defoliation. $(\mathrm{a}, \mathrm{b})$ Change of the stem morphology after defoliation. (c, d) Stoma on the abaxial and adaxial side of leaves. (e, f) Stoma on stem surface of the control and treatment. (g) Internode length and diameter of the stem. (h) Anthocyanin content. (i-l) Stomatal density, length, width and conductance. Different letters above bars indicate statistical significance $(P<0.05)$. Abbreviations: ND, non-detected.

Figure 6. Change of chlorophyll pigments (a, b), soluble sugar (c), $\mathrm{CO}_{2}$ assimilation (d, e), electron transport rate (f) and D1 protein and Rubsico in stems of Mikania micrantha during the tress of defoliation. $\mathrm{CO}_{2}$ assimilation (e) and electron transport rate (f) were measured on at day 20 of defoliation. Different letters above bars indicate statistical significance $(P<0.05)$. Abbreviations: ETR, electron transport rate; $\mathrm{P}_{\text {net }}$, net photosynthesis; $\mathrm{R}_{\text {day }}$, day respiration; $\mathrm{P}_{\text {gross }}$, gross photosynthesis, PPFD, photosynthetic photon flux density.

Figure 7. Change of subcellular structure in stems of Mikania micrantha 20 days after defoliation. (a-f) Transmission electron microscope image of leaves, control stem and defoliation stem. (g-i) Change of length, width and lengh:width ratio in the stem after defoliation. Different letters above bars indicate statistical significance $(P<0.05)$. Abbreviations: $\mathrm{CP}$, chloroplast; $\mathrm{CW}$, cell wall; $\mathrm{SG}$, starch grains. 

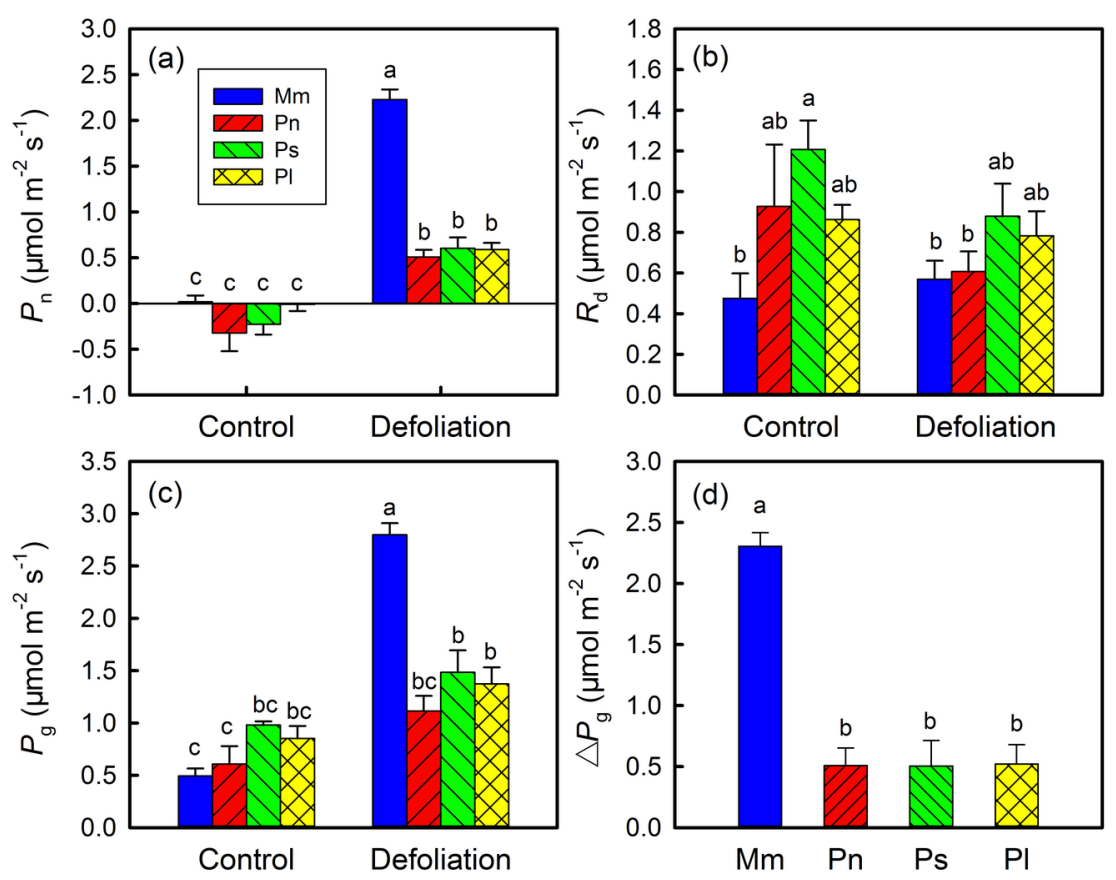

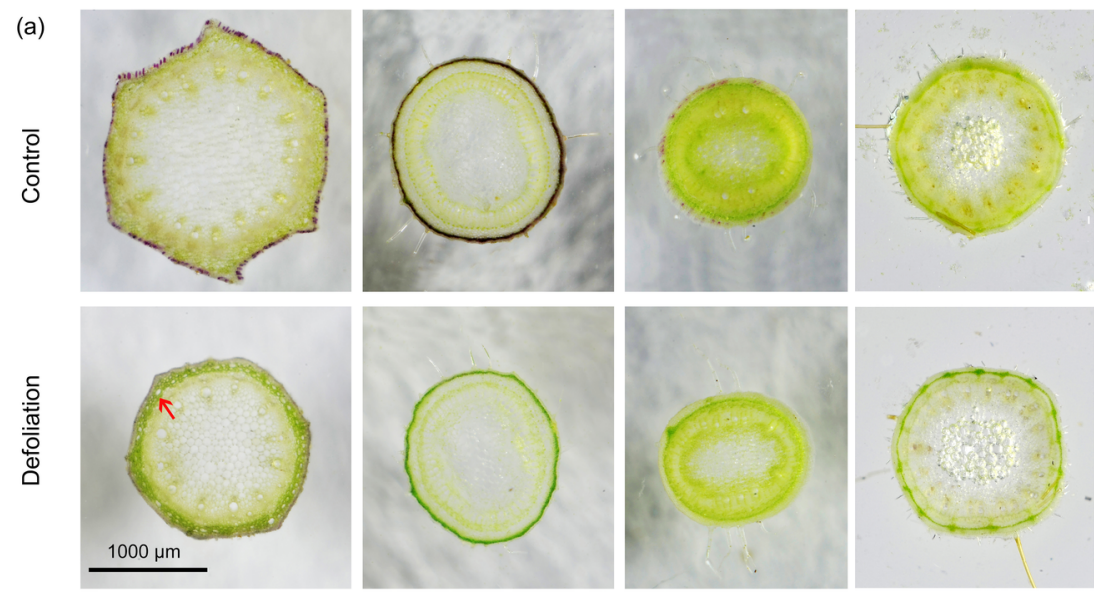

$\mathrm{Mm}$

Ps

PI
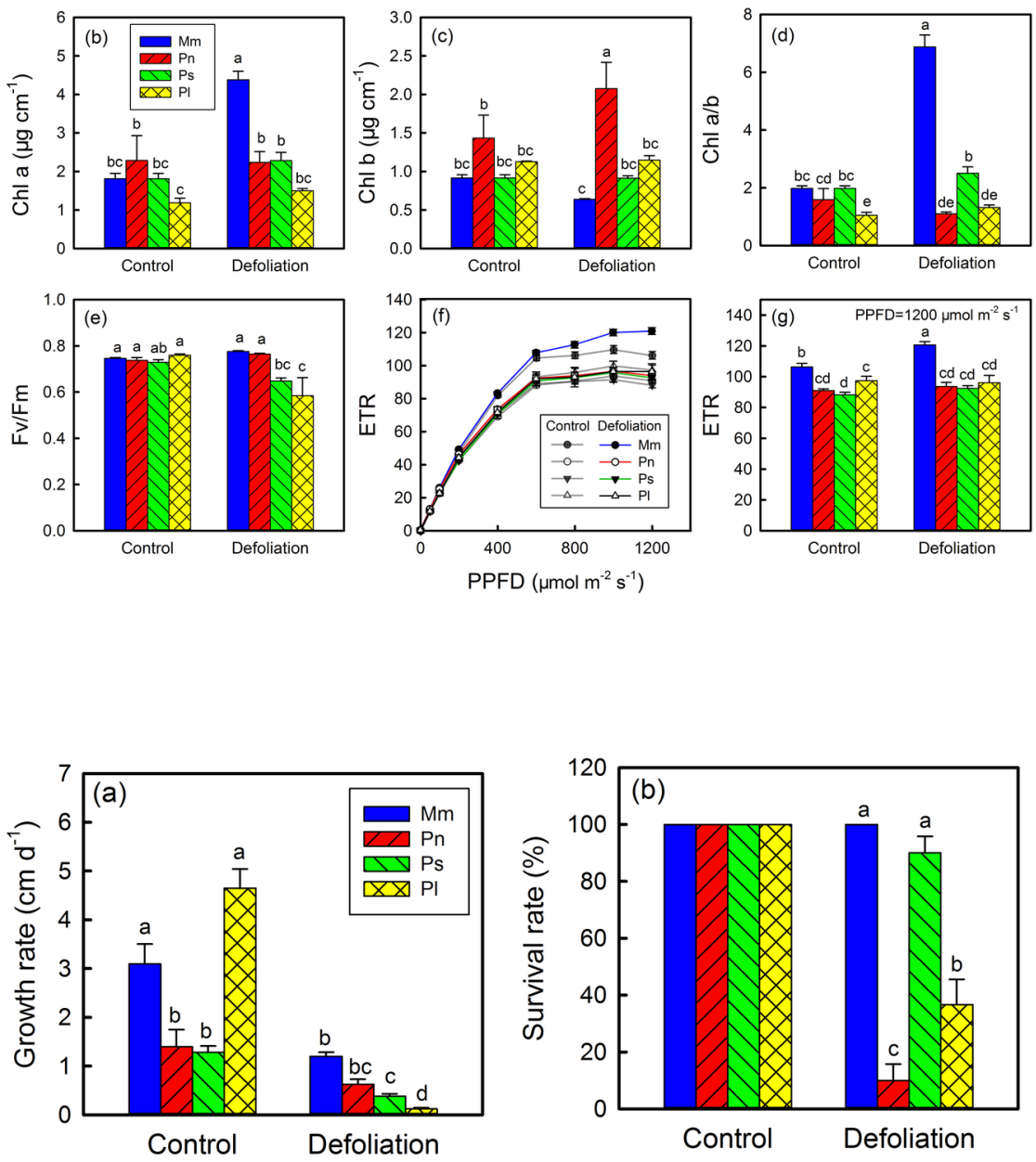
(a)
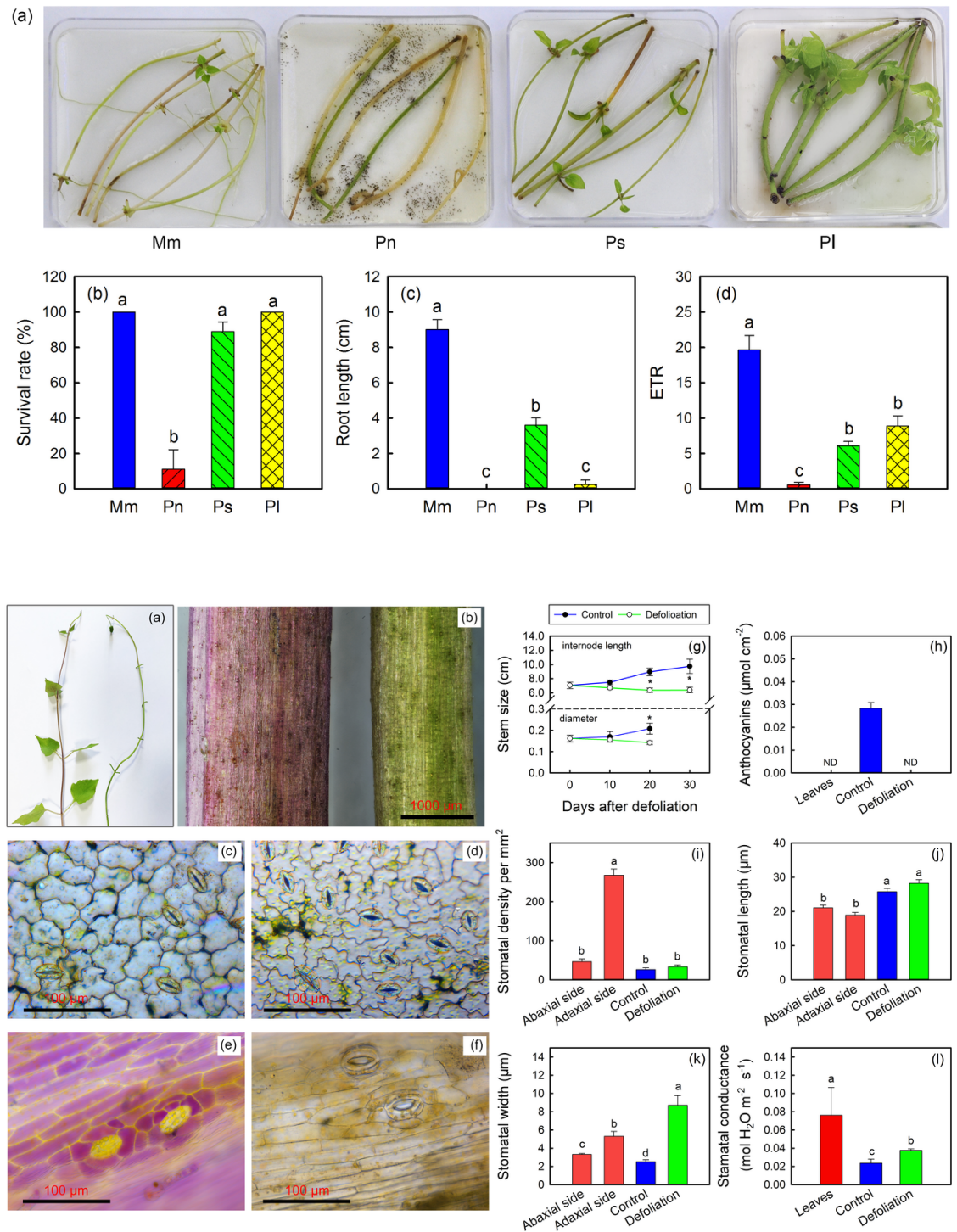

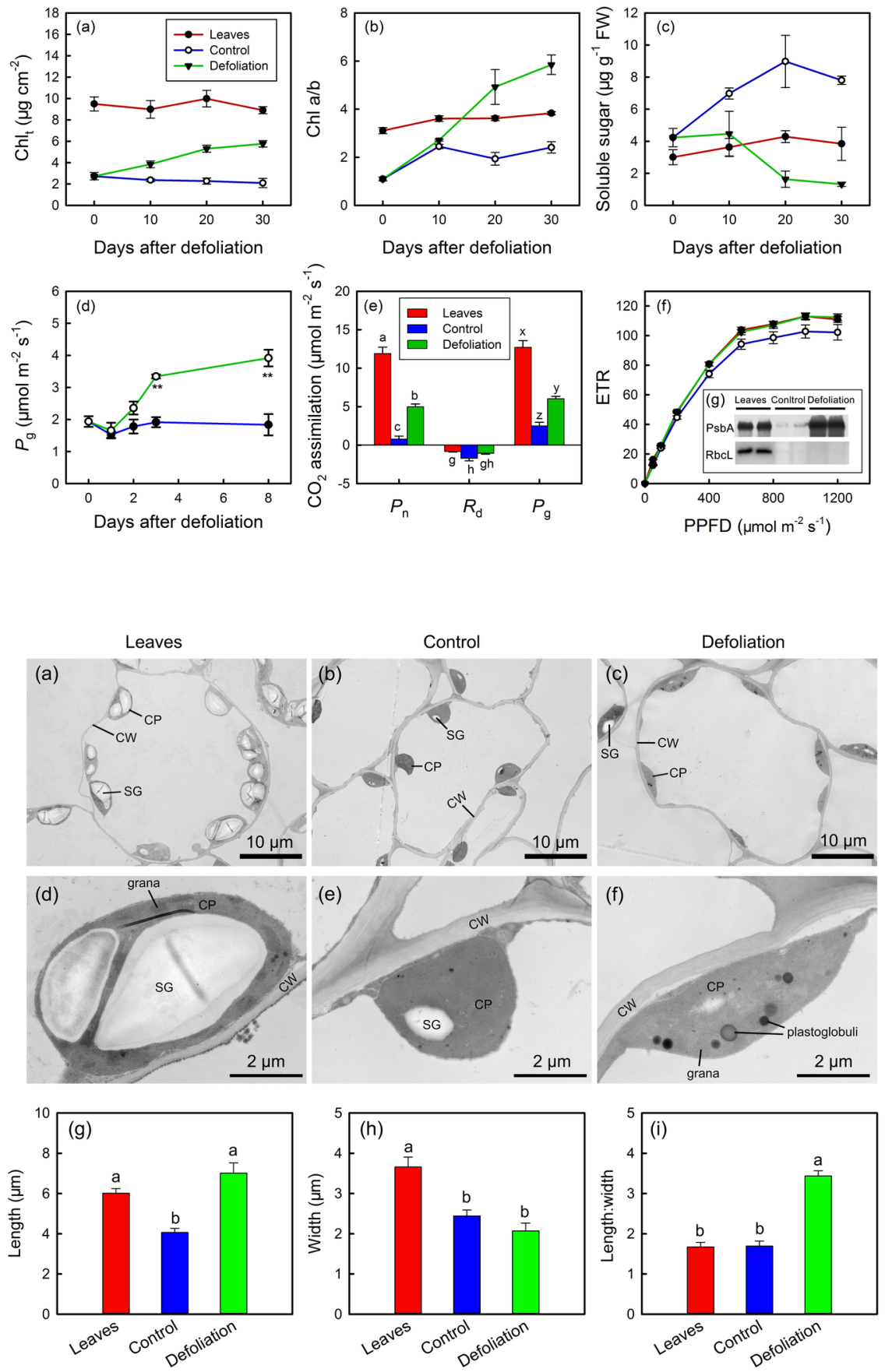